\title{
Resource allocation between somatic growth and reproductive output in the pelagic chordate Oikopleura dioica allows opportunistic response to nutritional variation
}

\author{
Christofer Troedsson ${ }^{1}$, Jean-Marie Bouquet ${ }^{1}$, Dag L. Aksnes ${ }^{2}$, Eric M. Thompson ${ }^{1, *}$ \\ ${ }^{1}$ Sars International Centre for Marine Molecular Biology, and ${ }^{2}$ Institute of Fisheries and Marine Science, \\ Bergen High Technology Centre, Thormøhlensgaten 55, 5008 Bergen, Norway
}

\begin{abstract}
Pelagic urochordate appendicularians are a vital component of marine zooplankton communities, second in abundance only to copepods. Found in all major ocean systems, they are capable of rapid blooms, attaining densities exceeding 53000 ind. $\mathrm{m}^{-3}$. We maintained a widely distributed species, Oikopleura dioica, under controlled laboratory conditions, and examined some key life history parameters, including growth rates, fecundity, and generation time, in response to varying temperature and food regimes. The results allowed us to divide the life cycle into 4 distinct phases, during which somatic growth of the animal appeared highly programmed as a function of temperature, but non-responsive to food concentrations exceeding a minimum level necessary for survival. All resources above this level were directed to the reproductive organ, yielding clear differences in fecundity as a function of food regime. Generation times and spawning windows were also independent of food concentration, but dependent on temperature. The generation time, which is extremely short for a complex metazoan, combined with high fecundity, yielded a relationship between animal size and maximal intrinsic rate of natural increase that considerably exceeded values recorded for other poikilothermic metazoans. Intrinsic rates of natural increase were similar to those determined for some algal species reproducing by binary fission, explaining the capacity of $O$. dioica to respond quickly and opportunistically to algal blooms.
\end{abstract}

KEY WORDS: Appendicularia $\cdot$ Life history $\cdot$ Zooplankton $\cdot$ Filter feeding $\cdot$ Semelparous

Resale or republication not permitted without written consent of the publisher

\section{INTRODUCTION}

Understanding factors that are critical determinants in the life history strategies of organisms is one of the fundamental challenges of modern ecology (Stearns 1992). Two key parameters in describing a given life history pattern are the investment of resource and time that organisms put into growth and reproduction. Among a set of life history parameters an optimum will be established and an organism will therefore have to

${ }^{*}$ Corresponding author. Email: eric.thompson@sars.uib.no compromise in the differential allocation of resources that are available to it. Invariably, trade-offs result between different life history characteristics, where increased benefits from one parameter are associated with decreased benefits from another. In this study, we examined growth and reproductive resource allocation in a key component of marine zooplankton, the urochordate appendicularian Oikopleura dioica.

One reason for the success of the pelagic appendicularians in marine ecosystems is that they are able to exploit a wide range of both live and dead organic particles spanning several orders of magnitude in size down to $0.2 \mu \mathrm{m}$ (Flood \& Deibel 1998). To do this, they 
live inside an elaborate multi-chambered extracellular house, complete with inlet and food-concentrating filters that they secrete from a specialised oikoplastic epithelium (Spada et al. 2001, Thompson et al. 2001). Among appendicularian species, Oikopleura dioica has a wide zoogeographic distribution, being found in the coastal waters of Europe, Asia, and the Americas, and is both eurythermal and euryhaline (Fenaux et al. 1998). O. dioica has generation times ranging from $1 \mathrm{~d}$ at 27 to $29^{\circ} \mathrm{C}$ (Hopcroft \& Roff 1995) to $16 \mathrm{~d}$ at $10^{\circ} \mathrm{C}$ (Uye \& Ichino 1995). This very short generation time is a particularly striking feature in a metazoan, enabling the animal to exploit favourable conditions rapidly. This may in part account for their patchy distribution and the observation that they can attain densities of 53000 ind. $\mathrm{m}^{-3}$ (Uye \& Ichino 1995). In view of their appropriate size range for ingestion by fish larvae and their capacity for rapid blooms, appendicularians are also likely to be an important factor for successful recruitment in several fish populations, which has been documented in plaice (Shelbourne 1962) and in sole (Gadomski \& Boelert 1984). From an experimental standpoint, $O$. dioica is advantageous in that it has been successfully cultured in the laboratory for prolonged periods (Gorsky 1980).

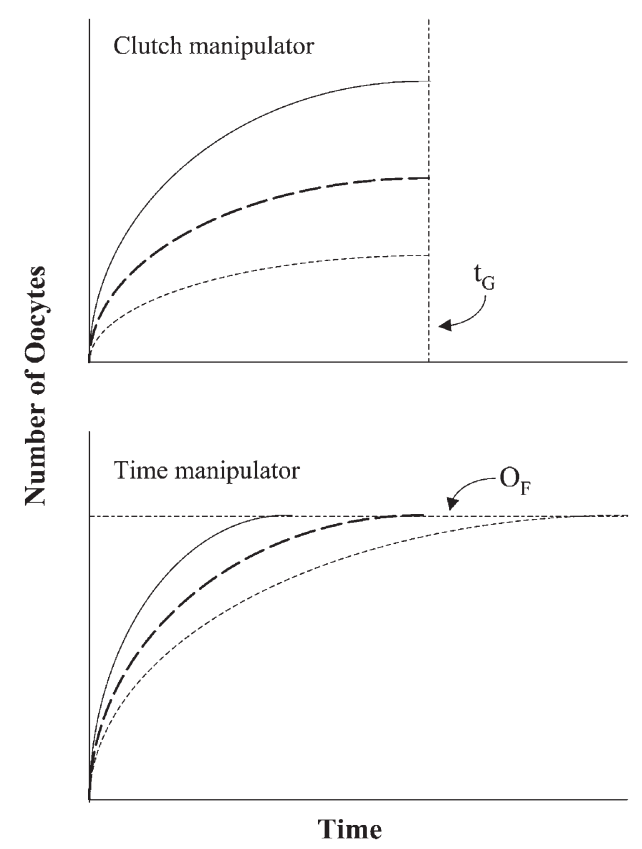

Fig. 1. Schematic diagram of different reproductive strategies of semelparous organisms. At one extreme, clutch manipulators with a fixed generation time $\left(t_{\mathrm{G}}\right)$ will produce different numbers of oocytes in response to varying nutrient conditions from low (dashed curve) to intermediate (bold dashed curve) to high (solid curve). At the other extreme, time manipulators will produce a fixed clutch size $\left(O_{\mathrm{F}}\right)$ by varying the generation time required to achieve this in response to varying nutrient conditions
A particularly interesting feature of the appendicularians is the complex extracellular house that is secreted from the oikoplastic epithelium. Replacement of the entire house structure is frequent, and discarded appendicularian houses in general are a significant component of marine snow and vertical carbon flux in the oceans (Silver \& Alldredge 1981). The total house carbon produced during the lifetime of Oikopleura dioica is 1.8 to 3.0 times the body carbon of a mature individual (Sato et al. 2001), suggesting substantial energetic investment. For this species, the strategy to invest a seemingly large amount of energy into a feeding structure must be placed in the context of a significant channelling of resources to the reproductive organ. When the semelparous $O$. dioica spawns and dies, the reproductive organ represents about $50 \%$ the size of the organism.

The optimisation approach to life history analyses proposes that natural selection will drive organisms to a particular set of trade-offs that has higher fitness than other combinations of trade-offs (Lack 1947, Stearns 1992). In iteroparous organisms with parental care, such as birds, this kind of analysis may become quite complicated. In semelparous organisms without parental care, such as Oikopleura dioica, the analysis is simplified. The maximal intrinsic rate of natural increase $\left(r_{\max }\right)$ that can be taken as a measure of fitness is then expressed as:

$$
r_{\max }=\frac{\ln b}{T}
$$

Hence, $r_{\max }$ is increased by increasing egg number (b) or by decreasing generation time $(T)$. Organisms that reduce generation time have been referred to as time manipulators, whereas those that increase fecundity are clutch manipulators (Aksnes \& Giske 1990) (Fig. 1). In general, a semelparous organism will tend to minimize generation time unless it has evolved such that generation time is synchronized with some environmental factors, for example a spring bloom, that enhances offspring survival. The optimal number of eggs, at a given generation time, is then a trade-off between the benefit and cost of producing the eggs.

Here, we investigated how the life history characteristics (egg number, generation time, spawning period and $r_{\max }$ ) of Oikopleura diocia responded to temperature and food availability. For each experimental condition, growth of the animals was monitored, and the number of eggs produced and the spawning window were determined. Despite the high rates of house production in this organism, somatic growth rates appeared to be surprisingly non-responsive to food availability beyond low threshold values. Variability in growth rates between the nutritive conditions was instead expressed entirely in the reproductive organ. 
If a minimum threshold food concentration was available, somatic growth appeared to be entirely a function of temperature. This enabled us to define a simple model with 4 distinct phases in the life history of Oikopleura dioica.

\section{MATERIALS AND METHODS}

Collection and culture of animals. Oikopleura dioica were collected in the coastal area of Bergen using a plankton net with a large-volume cod-end, and they were cultured in wet laboratory facilities. Animals were cultured in 61 plastic beakers (Cambro) using a plastic paddle $(25 \mathrm{~cm}$ deep $\times 7 \mathrm{~cm}$ wide) rotating at $15 \mathrm{rpm}$ to keep the animals and algae suspended in the water column. Seawater from a depth of 4 to $8 \mathrm{~m}$ was filtered through 3 Hytrex II Cartridge Filters (20, 10, and $1 \mu \mathrm{m}$, respectively). The filtered water was then passed through a Merck charcoal filter with a 0.25 to $-1.0 \mathrm{~mm}$ gradient and exposed to an Aqua-Care UVlight $(254 \mathrm{~nm}, 10 \mathrm{~W})$ to sterilise the water.

To establish a generation of animals, 40 to 45 mature females and 30 to 35 mature males were placed in 41 of water. The animals were monitored and forced to release their gametes into the water by gentle aspiration in a Pasteur pipette at full maturity. This was done to synchronise the population. After fertilisation the embryos were transferred, using 11 beakers, into fresh 61 beakers with the designated food and temperature regimes. After $24 \mathrm{~h}$ and $48 \mathrm{~h}$ the beakers were diluted 3-fold and 2-fold, respectively, within their assigned regime. Each successive $24 \mathrm{~h}$ after this, the animals were transferred with a $10 \mathrm{ml}$ Sterilin pipette with a cut tip, the diameter of which was wider than the maximum width of the house, to a fresh 61 beaker under the same experimental conditions.

Growth response. Standard culture conditions were established (J.-M. Bouquet et al. unpubl.) using 2 algae, Isochrysis galbana and Chaetoceros calcitrans. The animals were fed both algae, each at a concentration of 2000 cells $\mathrm{ml}^{-1}$ up to $96 \mathrm{~h}$ followed by 4000 cells $\mathrm{ml}^{-1}$ from this time point until spawning. Higher concentrations of algal cells resulted in increased mortality, apparently through increased filter clogging, while lower concentrations resulted in less successful spawns. In the limited food regime the animals were fed $1 / 6$ of the standard food concentration. The experiments were done at 15 and $20^{\circ} \mathrm{C}$. In some experiments, the animals were fed a range of 50 to 4000 cells $\mathrm{ml}^{-1}$ of each algal species, to investigate specific periods of growth. To test for differences in growth rates over this range, the Chow-test (Kennedy 1998, Kristoffersen \& Salvanes 1998) was performed. The Chow-test compares the residual sum of squares between 2 regressions:

$$
\mathrm{F}=\frac{\left[\sum \mathrm{S}_{\text {pool }}^{2}-\left(\sum \mathrm{S}_{\mathrm{A}}^{2}+\sum \mathrm{S}_{\mathrm{B}}{ }_{\mathrm{B}}\right)\right] / \mathrm{K}}{\left(\sum \mathrm{S}_{\mathrm{A}}{ }_{\mathrm{A}}+\sum \mathrm{S}_{\mathrm{B}}{ }_{\mathrm{B}}\right) /\left(\mathrm{n}_{\mathrm{A}}+\mathrm{n}_{\mathrm{B}}-2 \mathrm{~K}\right)}
$$

where $\Sigma S^{2}$ pool is the residual sum of squares for the pooled samples $\Sigma \mathrm{S}^{2}{ }_{\mathrm{A}}$ and $\Sigma \mathrm{S}^{2}{ }_{\mathrm{B}}$ that represent the residual sum of squares for the 2 growth regressions $A$ and $\mathrm{B}, \mathrm{K}$ is the number of regression parameters (here $\mathrm{K}=$ 2 , slope and intercept), and $\mathrm{n}_{\mathrm{A}}$ and $\mathrm{n}_{\mathrm{B}}$ are the sample sizes of $\mathrm{A}$ and $\mathrm{B}$. If the $F$-value were greater than the tabulated F-distribution for $\mathrm{p}=0.05$ for $\mathrm{K}$ degrees of freedom in the numerator and $n_{\mathrm{A}}+n_{\mathrm{B}}-2 \mathrm{~K}$ degrees of freedom in the denominator, then we would reject the hypothesis that the regression parameters are the same for the data sets.

The lengths of total body (BL) and reproductive organ alone (GL) were measured every $8 \mathrm{~h}$ from fertilisation. The trunk length (TL) of the animals was calculated as BL-GL. The BL was converted to ash-free dry weight (AFDW) using a BL-AFDW regression (Nakumura et al. 1997). The instantaneous growth rate (g) was calculated at the beginning of Phase 2 and Phase 3 , where the growth rate was constant throughout the phase.

$$
g=\left(\ln W_{2}-\ln W_{1}\right) /\left(t_{2}-t_{1}\right)
$$

In the equation, $W 1$ and $W 2$ represent the AFDW's at times $t_{1}$ and $t_{2}$, respectively. Phase 2 was defined from the expansion of the first house to when the reproductive organ started to grow. Phase 3 was defined from the start of reproductive organ growth until the spawning period, when the animals released their gametes.

Determination of egg number, generation time and spawning window. The number of eggs produced by the females was determined after culturing the animals at 2 different food concentrations at 15 and $20^{\circ} \mathrm{C}$. At the end of the life cycle, when no more houses were produced and no pre-houses were observed, the animals were transferred to a Merck $32 \mathrm{~mm}$ glass-staining jar and spawned naturally. The time of spawning and the number of eggs were recorded. Eggs were counted and analysed by microscope, as well as by image analysis using Media Cybernetics Cool-SNAP Pro Digital Capture Kit. Mean egg sizes were determined by measuring 5 eggs per individual from 20 individuals at both the standard and limited food concentrations.

The time of spawning was noted and the generation time was defined as the point at which $50 \%$ of the individuals in the population had spawned. The spawning window was defined as the first to the third quartile of spawning individuals. The maximal intrinsic rate of natural increase was calculated using Eq. (1). 


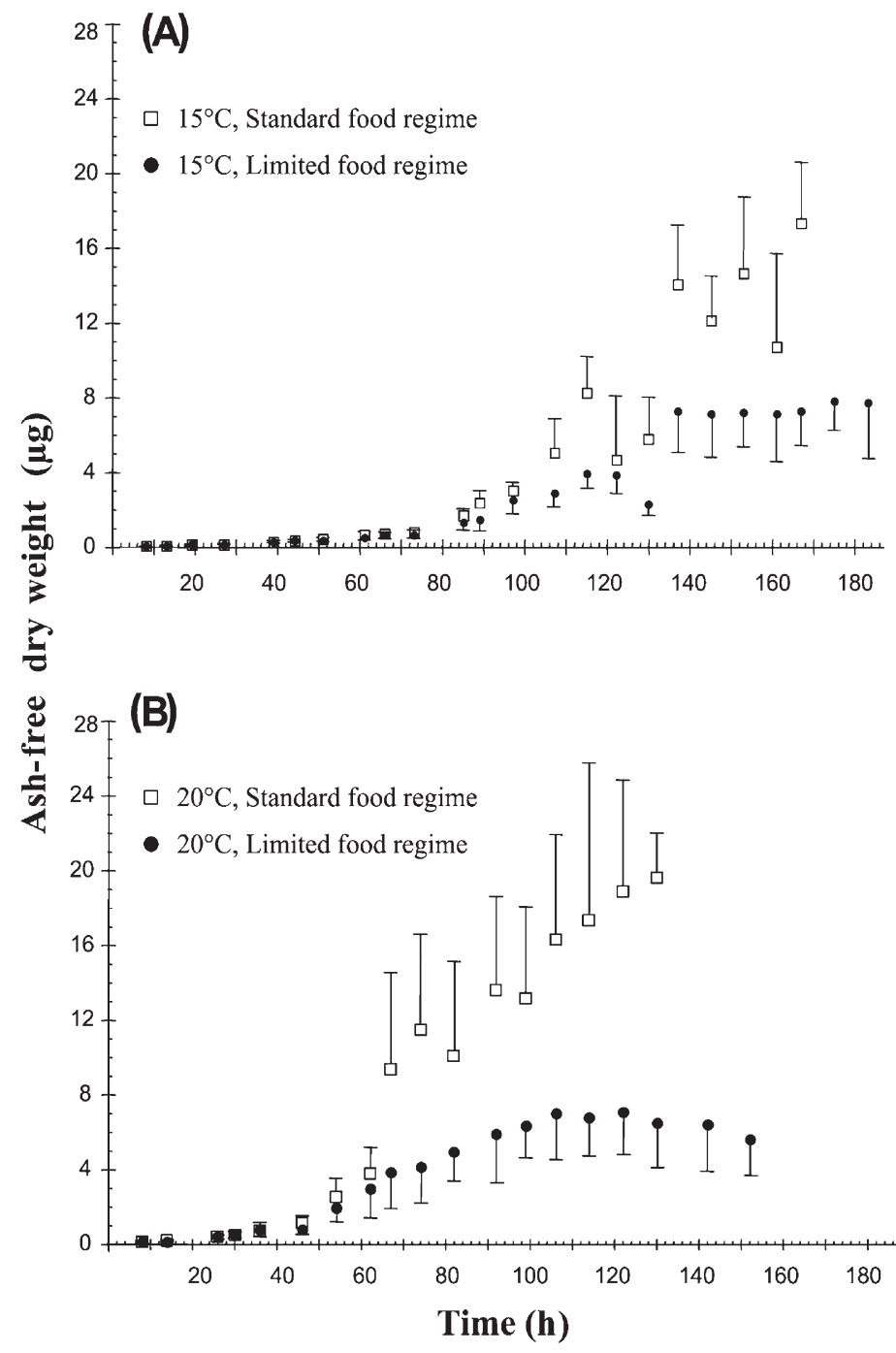

Fig. 2. Oikopleura dioica. Growth under different food and temperature regimes. Body length (BL) was measured throughout the life cycle of $O$. dioica at (A) $15^{\circ} \mathrm{C}$ and (B) $20^{\circ} \mathrm{C}$ under standard (ㅁ) and limited $(\bullet)$ food concentrations. BL was converted to ash-free dry weight (AFDW) by the regression $\log \mathrm{AFDW}=2.49 \log B L-6.22$. Vertical bars indicate the amplitude of the standard deviations
Statistical analyses and plots. All statistical analyses and curve fits were made using Statistica StatSoft (2000) software. For investigation of difference in a parameter between 2 groups, a $t$-test was performed after verification of homogeneity in the variance.

\section{RESULTS}

\section{Growth response}

There were significant differences in the growth response between standard and limited food concentrations at both 20 and $15^{\circ} \mathrm{C}$ (Fig. 2). The animals produced their first house immediately following metamorphosis, and during the period leading up to this point, growth was independent of food concentration, as the first filter-feeding house had not yet been expanded. At $20^{\circ} \mathrm{C}$ the first house was detected at $8 \mathrm{~h}$, and $50 \%$ of the population had produced their first house after $11 \mathrm{~h}$. At $15^{\circ} \mathrm{C}$ the first house was detected at $11 \mathrm{~h}$, and $50 \%$ of the population had produced their first house after $15 \mathrm{~h}$. We defined this period between fertilisation and production of the first house as 'Phase 1 ' in the life cycle. During 'Phase 2' between expansion of the first house up to the point when reproductive organ growth became measurable, growth was similar for standard and limited food regimes ( $t$-test: $15^{\circ} \mathrm{C}, \mathrm{df}=7, \mathrm{p}=0.63 ; 20^{\circ} \mathrm{C}$, df $=10$, $\mathrm{p}=0.21$ ) but was significantly different as a function of temperature ( $t$-test: df $=17, \mathrm{p}<0.001$ ) (Table 1$)$. A possible food regime effect during this phase was explored in more detail by culturing animals at 50, 100, 300, 500, 1000, 2000 and 4000 cells ml ${ }^{-1}$ (Fig. 3). A Chow-test $(\mathrm{p}<0.05)$ showed no significant differences in growth rate between these diverse food concentrations during Phase 2 (Table 2), indicating that the animals have a fixed somatic growth rate that did not vary with food concentration, but was dependent on temperature.

Table 1. Oikopleura dioica. Growth rates under different food and temperature regimes. Phase 2 is defined as the period between the appearance of the first house and the point when measurable growth of the gonad commences. Phase 3 is defined as the period between the start of measurable gonad growth until spawning commences. The instantaneous growth rate is the relative increase in body mass between the start and end of a $24 \mathrm{~h}$ period, here the start of Phases 2 and 3

\begin{tabular}{|c|c|c|c|c|c|}
\hline \multirow[t]{2}{*}{ Food regime } & \multirow{2}{*}{$\begin{array}{c}\text { Temperature } \\
\left({ }^{\circ} \mathrm{C}\right)\end{array}$} & \multicolumn{2}{|c|}{ Phase 2} & \multirow[b]{2}{*}{$\begin{array}{c}\text { Growth rate } \\
\left(\mathrm{ng} \mathrm{h}^{-1} \pm \mathrm{SD}\right)\end{array}$} & \multirow{2}{*}{$\begin{array}{r}\text { Phase } 3 \\
\text { Instantaneous } \\
\text { growth rate }\left(\mathrm{d}^{-1}\right)\end{array}$} \\
\hline & & $\begin{array}{c}\text { Growth rate } \\
\left(\mathrm{ng} \mathrm{h}^{-1} \pm \mathrm{SD}\right)\end{array}$ & $\begin{array}{l}\text { Instantaneous } \\
\text { growth rate }\left(\mathrm{d}^{-1}\right)\end{array}$ & & \\
\hline \multirow[t]{2}{*}{ Standard } & 20 & $52.9 \pm 1.7$ & 2.0 & $393 \pm 67$ & 1.3 \\
\hline & 15 & $22.1 \pm 2.9$ & 1.3 & $220 \pm 67$ & 1.3 \\
\hline \multirow[t]{2}{*}{ Limited } & 20 & $48.5 \pm 6.7$ & 1.9 & $191 \pm 75$ & 0.8 \\
\hline & 15 & $25.5 \pm 4.9$ & 1.4 & $59 \pm 33$ & 0.5 \\
\hline
\end{tabular}




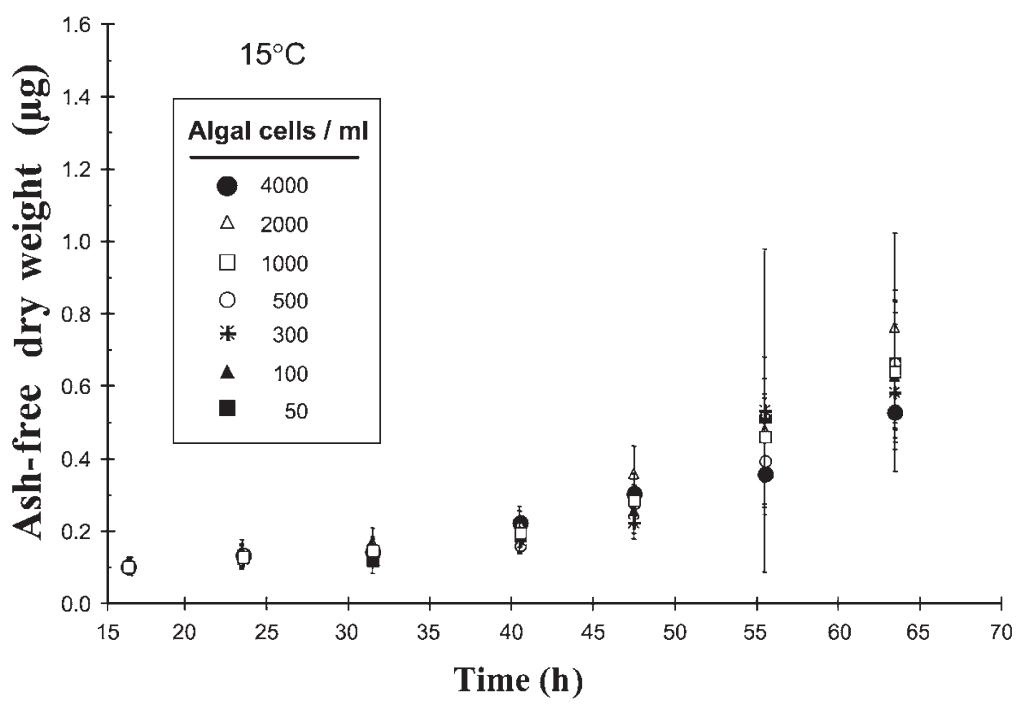

Fig. 3. Oikopleura dioica. Growth under different food regimes during Phase 2 of the life cycle. Animals were cultured in algal concentrations of 50, 100, 300, 500, 1000, 2000, and 4000 cells ml$^{-1}$. AFDWs were determined as in Fig. 2 by sampling animals during the period between expansion of the first house up to the point when reproductive organ growth began. Vertical bars indicate the amplitude of the standard deviations. No significant differences in growth were observed among the different food concentrations (see Table 3 for statistical analyses)

food conditions. In fact, when the ratio of trunk sizes alone in standard versus limited food conditions was plotted throughout the life cycle, it was constant around 1.0 (Fig. 4B). This was not the case for the ratio of reproductive organ sizes under the standard and limited nutritive conditions, where the reproductive organ became clearly larger under the former conditions (Fig. 4B). Taken together, these results imply that the animals allocated all the energy available to them over a given threshold, defined as the minimum amount of energy required to maintain survival, towards growth of the reproductive organ.

\section{Oocyte production}

In the fourth phase, characterized by release of gametes, the reproductive output was significantly different between the 2 food regimes. The limited food regime produced a significantly lower number of eggs (Table 3)

Phase 3 was defined as the period between the end of Phase 2 when the reproductive organ had started to grow and the beginning of spawning. Growth during this period was dependent on both temperature and food. During this phase, significant differences in growth were measured between the food regimes for $20^{\circ} \mathrm{C}$ ( $t$-test: $\left.\mathrm{df}=8, \mathrm{p}=0.02\right)$ as well as $15^{\circ} \mathrm{C}$ ( $t$-test: $\mathrm{df}=8, \mathrm{p}<0.01$ ) (Table 1, Fig. 2). The key difference was that there was considerably greater growth of the reproductive organ under the standard food conditions. In Fig. 4A it is evident that the contribution of TL to BL remained higher under limited than under standard
( $t$-test: $15^{\circ} \mathrm{C}, \mathrm{df}=62, \mathrm{p}<0.001 ; 20^{\circ} \mathrm{C}$, df $=110 \mathrm{p}<$ $0.001)$. The mean size of eggs was $95.0 \pm 6.5 \mu \mathrm{m}$ at standard food concentrations and $94.9 \pm 4.8 \mu \mathrm{m}$ at limited concentrations revealing no significant difference ( $t$-test: $\mathrm{df}=196, \mathrm{p}=0.88$ ) in the size of individual eggs under the 2 different nutritive conditions.

\section{Generation time and spawning duration}

There were no significant differences in spawning duration between standard and limited food regimes

Table 2. Oikopleura dioica. Pairwise statistical comparisons growth under different food regimes during Phase 2 at $15^{\circ} \mathrm{C}$. F-distribution values are given for the Chow-test $(p<0.05)$. No significant pairwise differences were observed. Correlation coefficients are given for the regressions on individual food concentrations during the Phase 2 growth period

\begin{tabular}{|c|c|c|c|c|c|c|c|}
\hline \multirow{2}{*}{$\begin{array}{l}\text { Algal food } \\
(\text { cells ml-1) }\end{array}$} & \multicolumn{7}{|c|}{ Pairwise F-distribution values ${ }^{\mathrm{a}}$} \\
\hline & $\begin{array}{c}50 \\
\left(\mathrm{r}^{2}=0.58\right)\end{array}$ & $\begin{array}{c}100 \\
\left(\mathrm{r}^{2}=0.70\right)\end{array}$ & $\begin{array}{c}300 \\
\left(\mathrm{r}^{2}=0.63\right)\end{array}$ & $\begin{array}{c}500 \\
\left(\mathrm{r}^{2}=0.67\right)\end{array}$ & $\begin{array}{c}1000 \\
\left(r^{2}=0.75\right)\end{array}$ & $\begin{array}{c}2000 \\
\left(\mathrm{r}^{2}=0.75\right)\end{array}$ & $\begin{array}{c}4000 \\
\left(\mathrm{r}^{2}=0.72\right)\end{array}$ \\
\hline 50 & & $0.63(2,206)$ & $0.20(2,200)$ & $0.93(2,216)$ & $0.18(2,208)$ & $1.86(2,212)$ & $0.24(2,217)$ \\
\hline 100 & & & $0.07(2,215)$ & $0.24(2,228)$ & $0.13(2,224)$ & $1.18(2,226)$ & $0.45(2,232)$ \\
\hline 300 & & & & $0.39(2,222)$ & $0.29(2,218)$ & $0.17(2,221)$ & $0.28(2,227)$ \\
\hline 500 & & & & & $0.36(2,231)$ & $1.05(2,232)$ & $0.32(2,240)$ \\
\hline 1000 & & & & & & $0.23(2,229)$ & $0.14(2,235)$ \\
\hline 2000 & & & & & & & $0.73(2,238)$ \\
\hline 4000 & & & & & & & \\
\hline
\end{tabular}


Table 3. Oikopleura dioica. Generation time, spawning duration (defined in 'Materials and methods') and the number of oocytes produced in standard and limited food concentrations at 20 and $15^{\circ} \mathrm{C} . r_{\text {max }}$ : maximal intrinsic rate of natural increase

\begin{tabular}{|c|c|c|c|c|c|}
\hline Food regime & $\begin{array}{c}\text { Temperature } \\
\left({ }^{\circ} \mathrm{C}\right)\end{array}$ & $\begin{array}{c}\text { Spawning } \\
\text { duration }(\mathrm{h} \pm \mathrm{SD})\end{array}$ & $\begin{array}{c}\text { Number of } \\
\text { oocytes }\end{array}$ & $\begin{array}{c}\text { Generation } \\
\operatorname{time}^{\mathrm{a}}(\mathrm{h} \pm \mathrm{SD})\end{array}$ & $\begin{aligned} r_{\max } \\
\left(\mathrm{d}^{-1}\right)\end{aligned}$ \\
\hline \multirow[t]{2}{*}{ Standard } & 20 & $17.3 \pm 7.9$ & $363 \pm 172$ & $132 \pm 13$ & 1.07 \\
\hline & 15 & $15.7 \pm 5.1$ & $303 \pm 115$ & $159 \pm 20$ & 0.86 \\
\hline \multirow[t]{2}{*}{ Limited } & 20 & $20.7 \pm 7.1$ & $137 \pm 65$ & $132 \pm 11$ & 0.89 \\
\hline & 15 & $21.2 \pm 7.9$ & $142 \pm 64$ & $173 \pm 12$ & 0.69 \\
\hline
\end{tabular}

( $t$-test: $\left.15^{\circ} \mathrm{C}, \mathrm{df}=10, \mathrm{p}=0.19 ; 20^{\circ} \mathrm{C}, \mathrm{df}=12, \mathrm{p}=0.43\right)$. Furthermore, there were no significant differences in generation times between the 2 food regimes $(t$-test:
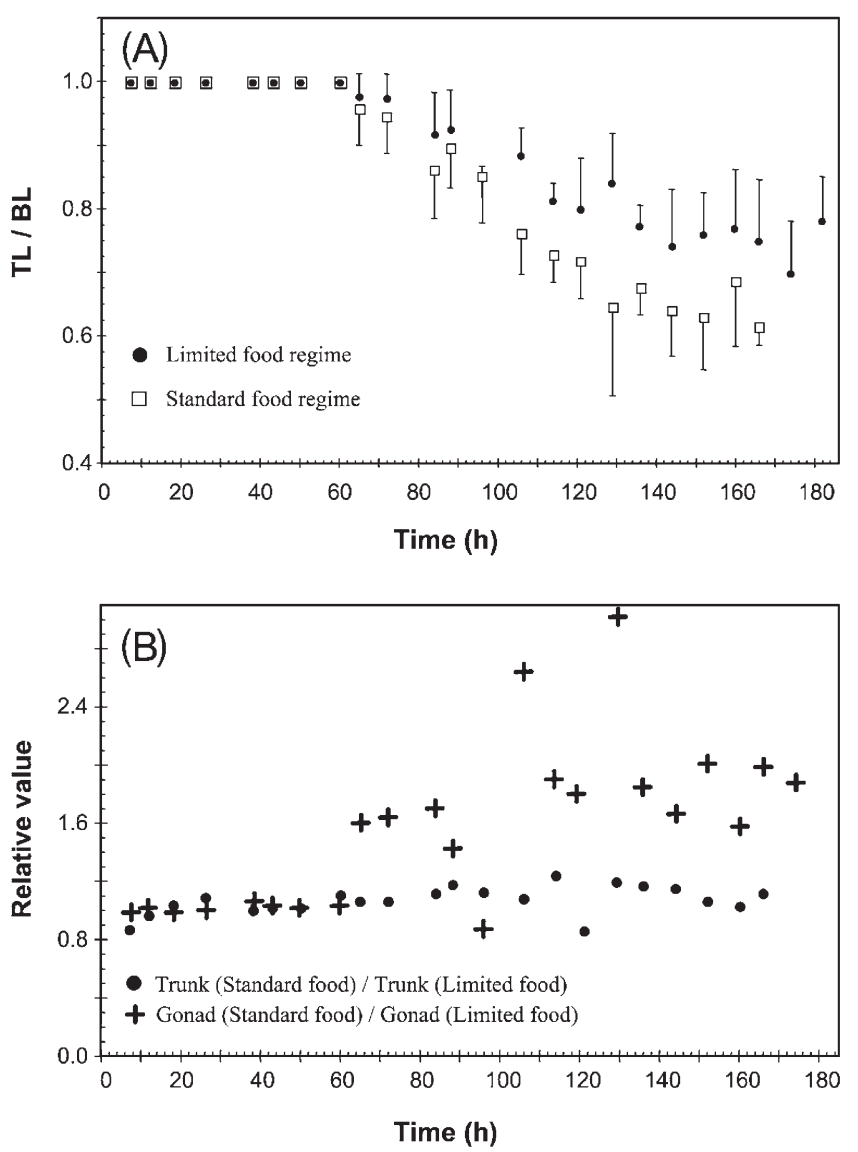

Fig. 4. Oikopleura dioica. The relative contributions of somatic trunk growth and reproductive organ growth to total growth at $15^{\circ} \mathrm{C}$ under different food regimes. (A) The relative contribution of the trunk length (TL) to body length (BL) under standard () and limited food concentrations $(\bullet)$ over the lifetime of the animals at $15^{\circ} \mathrm{C}$. Bars indicate the amplitude of the standard deviations. (B) The ratios between TLs $(\bullet)$ and gonad lengths (GLs) (+) in standard versus limited food concentrations. The sets of curves at $20^{\circ} \mathrm{C}$ show similar profiles shifted to earlier times (data not shown) $\left.15^{\circ} \mathrm{C}, \mathrm{df}=10, \mathrm{p}=0.25 ; 20^{\circ} \mathrm{C}, \mathrm{df}=11, \mathrm{p}=0.94\right)$. There was a significant difference between the generation times of populations at different temperatures ( $t$-test, $\mathrm{df}=23, \mathrm{p}<0.001)$. The generation time was $5.5 \mathrm{~d}$ at $20^{\circ} \mathrm{C}$, and $6.9 \mathrm{~d}$ at $15^{\circ} \mathrm{C}$ (Table 3 ).

\section{DISCUSSION}

At first glance, the filter-feeding strategy of Oikopleura dioica, involving frequent replacement of the filtering house structure, appears to be energetically demanding. Values for house renewal rates in this species have been reported from 4.1 to 19 houses $\mathrm{d}^{-1}$ (Flood \& Deibel 1998, Sato et al. 2001) and each newly secreted house represents about $15 \%$ of total body carbon (Sato et al. 2001). At a given point in time, there are often 2 to 3 pre-house rudiments present in addition to the actual inflated functioning house, representing an investment of up to $60 \%$ of total body carbon per unit time. On the other hand, Acuña (2001) has recently further developed arguments initially proposed by Harbison (1992), to suggest that the gelatinous houses of filter-feeding pelagic urochordates are in fact an adaptation to low food levels, which has enabled these organisms to successfully colonise large areas of oligotrophic oceanic environments. If indeed the production of houses is relatively costly compared to the overall energy budget of the semelparous $O$. dioica, questions arise as to what the preferred reproductive strategy is when food becomes limiting. As can be seen from the equation defining $r_{\max }$, the intrinsic rate of natural increase is maximised by reducing the generation time and increasing the number of eggs at spawning. These 2 traits, however, are in conflict.

An organism that grows larger, and accumulates greater energy reserves, is in general capable of producing more gametes of better quality. As Oikolpeura dioica grows, production of the next larger house with an increased total carbon content, would allow it to continue feeding in order to continue growing and to accumulate further reserves. A larger oikoplastic epithelium is required to produce a larger house. Since 
the epithelium covers the entire trunk of the animal, increased somatic growth is intimately and directly linked to the process of house renewal. When food is limiting, it may be preferable to divert energy from house production and growth into reproductive allotment, thus spawning at a smaller size. Also, the investment in houses that would be required to support a larger body would become too great, and energetic allocation towards the reproductive organ would occur sooner. This has been shown in Drosophila spp. (Bakker 1959, Robertson 1963). When nutrients are limiting, larvae pupate at a smaller size than normal, and these pupae produce fertile but small adult flies.

In the current study we have found that somatic growth in Oikopleura dioica, while dependent on temperature, was non-responsive to increasing nutrient availability beyond a threshold level required for the survival of the animal. This fits well with recent data (Sato et al. 2001) suggesting that food concentrations within the range of those normally encountered by this species do not appear to be a critical determinant in regulating house renewal rates. As shown previously, there was a strong dependence of the generation time on temperature, but there was no significant effect of the different food regimes on this parameter, or on the duration of spawning. There was a clear effect of food concentration on the number of eggs produced. These data suggest a characterisation of the life cycle of $O$. dioica into 4 distinct phases (Fig. 5). The growth rates and duration of each phase were dependent on temperature. It can be seen in Fig. 2 that under the limited food regime, overall growth appears to reach a plateau significantly prior to spawning. This is because the gonad first forms as a sac in which the central zone contains little to no material. Under limited food conditions, the number of eggs or sperm produced will suffice only to occupy the available space in the gonad. Under standard conditions, the number of gametes produced largely exceeds this minimal available space and the gonad continues to expand to accommodate this.

During the first phase up to the tail-shift metamorphosis of the animal, maternal resources stocked in the oocyte assure correct development, and no significant growth occurs. Inflation of the first house and commencement of filter feeding mark the beginning of the second phase, and detectable growth of the reproductive organ denotes the end. During this period somatic growth is fixed as a function of temperature and is independent of food concentration over a threshold level required to simply assure survival of the animal. Some preliminary observations (C. Troedsson \& E. M. Thompson unpubl.) indicate that the animal may be able to complete somatic growth throughout the life cycle at quite low nutrient levels entirely in the form of dissolved organic material. Under these conditions, however, the animals were unable to produce viable gametes. During Phase 2, energetic allocation was directed towards somatic growth, and the instantaneous growth rate was near the upper limit of that previously observed at these temperatures (Hopcroft \& Roff 1995). Throughout Phase 3, all available nutrition above the threshold level was allocated to growth of the reproductive tissue, and this accounted for the entire difference in overall size of the animals under the different food regimes. The weight increase during this period was significantly higher than in the second growth phase, although the instantaneous growth rate was lower or equal, reflecting the larger size of the animals at this time. Compared to previous recorded values, the instantaneous growth rates in this interval ranged from lower figures at the limited food concentrations to average values in the standard food concentrations (Hopcroft \& Roff 1995). The differences in growth during Phase 3 were expressed as a clear dif-

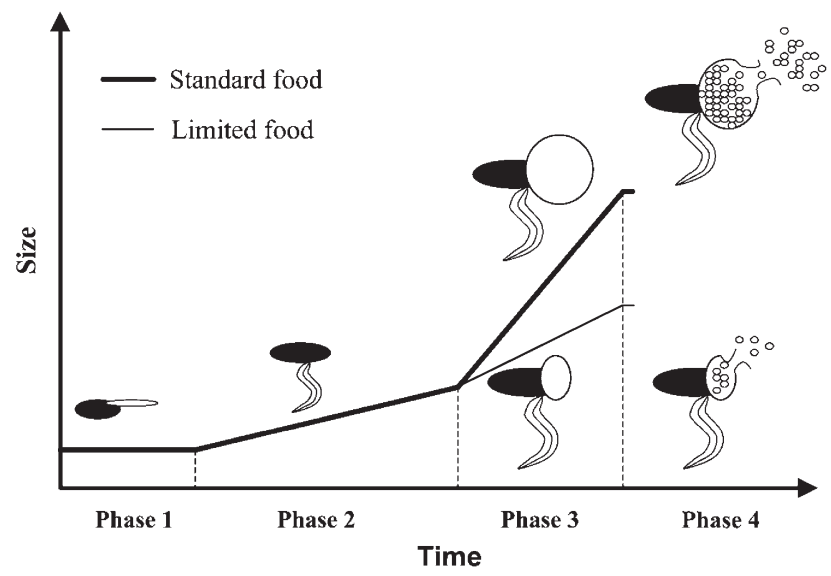

Fig. 5. Oikopleura dioica. Schematic representation of the life cycle under standard (thick line) and limited (thin line) food regimes. In Phase 1, the animal develops using maternal resources and does not actively feed. Growth is independent of external food concentration and the rate of development is dependent on temperature. During Phase 2 a minimum threshold amount of food is required. If food availability is below this threshold the animals will die. However, growth rate during this phase is independent of any excess food above the threshold amount. The rate of growth during this period is again dependent on temperature. In Phase 3 growth is dependent on both food concentration and temperature. The differential rate of growth between the standard and limited food regimes is expressed entirely in the reproductive organ. There is no difference in growth of the trunk between the 2 different food regimes during this phase. During Phase 4 , the animals spawn and die. At a given temperature, animals spawning in the limited food regime produce fewer oocytes, but there are no significant differences in duration of spawning and generation time. At higher temperatures the animals spawn earlier, with a concomitant shortening in the generation time 
ference in the reproductive output during Phase 4 . No significant differences in generation time or in duration of the spawning period were detected in the different food concentrations. These observations agree well with the proposition that the gelatinous filterfeeding strategy of pelagic urochordates may allow continuous low-cost monitoring of oligotrophic environments with an opportunistic response to favourable food conditions (Acuña 2001). Indeed, Oikopleura dioica is known to show rapid and extensive population growth in response to algal blooms (Hopcroft \& Roff 1995, Uye \& Ichino 1995, Nakamura et al. 1997). These features are also found in the related, gelatinous, filter-feeding urochordate salps, which attain growth rates as high as $10 \%$ of body weight $\mathrm{h}^{-1}$ and can have generation times as short as $2 \mathrm{~d}$ (Heron 1972). As can be seen from the intrinsic rate of natural increase $\left(r_{\max }\right)$ (Table 2$)$, the values for O. dioica ranging from $0.68 \mathrm{~d}^{-1}$ to $1.07 \mathrm{~d}^{-1}$ are well above the normal range for a metazoan of this size (Fenchel 1974). These intrinsic rates are similar to those of some phytoplankton species (Eppley 1972) that reproduce by binary fission and have doubling times of 15.5 to $24.1 \mathrm{~h}$.

By increasing the number of eggs at spawning, an organism will increase population growth, but inspection of the $r_{\max }$ equation reveals that it is more effective to reduce generation time. This latter strategy appears to be that adopted by Oikopleura dioica. At both temperatures, generation time and spawning window were independent of food concentration, but the different food regimes had a clear impact on the number of oocytes produced at spawning, suggesting that $O$. dioica is a clutch manipulator.

Thus, Oikopleura dioica appears to be an opportunistic r-selected species with programmed rates of somatic growth that are temperature-dependent. Both house production and somatic growth appear nonresponsive to regulation by food concentrations above a minimal threshold level required for survival. This leaves open the question as to what does regulate rates of house renewal in this species. Some clues may be provided by studies on the oikoplastic epithelium (Ganot \& Thompson 2002), the specialised organ that secretes the oikopleurid house. The number of cells in this epithelium is fixed at metamorphosis (about 2000), and subsequently, the epithelium (and in parallel, house size) grows entirely by endoreduplication of cellular DNA contents with concomitant increase in cell sizes. Different fields of cells in the epithelium attain different levels of ploidy, and the differential regulation of cell cycle lengths at the level of individual cells appears to be essential for the co-ordinate regulation of production of the diverse protein components required to build the house structure. The intricate clocking process co-ordinating the growth of the epi- thelium seems to be established prior to metamorphosis. Therefore it may become too complex to superimpose additional layers of potential regulatory responses onto this already intricate process. An elegant solution is to link regulation of the nutrient acquiring house-building function to basic metabolic rate control via temperature, in a process where somatic growth (including the epithelium) requires minimal nutritional input and any additional energy available is directed entirely to reproductive output in a short life cycle. Indeed, the life cycle of $O$. dioica is astonishingly short for a chordate organism and in addition, it has a surprisingly small genome size (72 Mb; Seo et al. 2001) for such a complex metazoan. Studies in birds indicate some correlation between genome size and life cycle length (Monaghan \& Metcalf 2000) and the situation in $O$. dioica is suggestive, but any conclusion awaits more extensive analysis.

The short life cycle, small genome size, and laboratory culture of Oikopleura dioica make it attractive for genetic studies of chordate innovations but also make for a compelling model organism linking basic cell and molecular biology to environmental responses. We have developed a number of molecular markers for the house building process (Spada et al. 2001, Thompson et al. 2001) and somatic growth, and are increasing this repertoire to include key molecular markers of reproductive investment. This will enable us to further the analyses presented here, by examining changes in targeted gene expression patterns in this organism as a primary response to environmental fluctuations.

Acknowledgements. We thank Gabriel Gorsky, Marine Station, Villefranche, for initial advice on setting up the culture of Oikopleura dioica, Jon Vidar Helvik, University of Bergen, for use of microscope imaging facilities, and Russell Hopcroft, University of Alaska, and members of the Thompson laboratory for helpful discussions. This work was supported by grant 145326/432 from the Norwegian Research Council (E.M.T.)

\section{LITERATURE CITED}

Acuña J (2001) Pelagic tunicates: why gelatinous? Am Nat 158:100-107

Aksnes D, Giske J (1990) Habitat profitability in pelagic environments. Mar Ecol Prog Ser 64:209-215

Bakker K (1959) Feeding period, growth and pupation in larvae of Drosophila melanogaster. Entomol Exp Appl 2:171-186

Eppley R (1972) Temperature and phytoplankton growth in the sea. Fish Bull 70:1063-1085

Fenaux R, Bone Q, Deibel D (1998) Appendicualria distribution and zoogeography. In: Bone Q (ed) The biology of pelagic tunicates. Oxford University Press, New York, p 251-264

Fenchel T (1974) Intrinsic rate of natural increase: the relationship with body size. Oecologica 14:317-326

Flood P, Deibel D (1998) The appendicularian house. In: Bone Q (ed) The biology of pelagic tunicates. Oxford University Press, New York, p 105-124 
Gadomski D, Boelert G (1984) Feeding biology of the pelagic larvae of English sole Parophys vetulus and butter sole Isopsetta isolepsis off the Oregon coast. Mar Ecol Prog Ser 20:1-12

Ganot PG, Thompson EM (2002) Patterning through differential endoreduplication in epithelial organogenesis of the chordate, Oikopleura dioica. Dev Biol (in press)

Gorsky G (1980) Optimisation des cultures d'appendiculaires: approche du metabolisme de O. dioica. PhD thesis, University of Paris VI

Harbison G (1992) The gelatinous inhabitants of the ocean interior. Oceanus 35:18-23

Heron A (1972) Population ecology of a colonizing species: the pelagic tunicate Thalia democratica. Oecologia 10: 269-293

Hopcroft R, Roff J (1995) Zooplankton growth rates: extraordinary production by the larvacean Oikopleura dioica in tropical waters. J Plankton Res 17:205-220

Kennedy P (1998) A guide to econometrics. Blackwell Publishers, Oxford

Kristoffersen J, Salvanes A (1998) Life history of Maurolicus muelleri in fjordic and oceanic environments. J Fish Biol 53:1324-1341

Lack D (1947) The significance of clutch size. Ibis 89:302-352

Monaghan P, Metcalfe NB (2000) Genome size and longevity. Trends Genet 16:331-332

Nakamura Y, Suzuki K, Suzuki S, Hiromi J (1997) Production of Oikopleura dioica (Appendicularia) following a picoplankton 'bloom' in a eutrophic coastal area. J Plankton Res 19:113-124

Editorial responsibility: Howard Browman (Contributing Editor), Storebø, Norway
Robertson F (1963) The ecological genetics of growth in Drosophila. 6. The genetic correlation between the duration of the larval period and body size in relation to larval diet. Genet Res 4:74-92

Sato R, Tanaka Y, Ishimaru T (2001) House production by Oikopleura dioica (Tunicata, Appendicularia) under laboratory conditions. J Plankton Res 23:415-423

Seo H, Kube M, Edvardsen R, Jensen M and 7 others (2001) Miniature genome in the marine chordate Oikopleura dioica. Science 294:2506

Shelbourne J (1962) A predator-prey size relationship for plaice larvae feeding on Oikopleura. J Mar Biol Assoc UK 42:243-252

Silver M, Alldredge A (1981) Bathypelagic marine snow: deep-sea algal and detrital community. J Mar Res 39: 501-530

Spada F, Steen H, Troedsson C, Kallesøe T, Spriet E, Mann M, Thompson EM (2001) Molecular patterning of the oikoplastic epithelium of the larvacean tunicate Oikopleura dioica. J Biol Chem 276:20624-20632

Stearns SC (1992) The evolution of life histories. Oxford University Press, New York

Thompson EM, Kallesøe T, Spada F (2001) Diverse genes expressed in distinct regions of the trunk epithelium define a monolayer cellular template for construction of the oikopleurid house. Dev Biol 238:260-273

Uye S, Ichino S (1995) Seasonal variations in abundance, size composition, biomass and production rate of Oikopleura dioica (Fol) (Tunicata: Appendicularia) in a temperate eutrophic inlet. J Exp Mar Biol Ecol 189:1-11

Submitted: April 3, 2002; Accepted: June 10, 2002

Proofs received from author(s): October 15, 2002 